\title{
Extended Intermolecular Interactions Governing Photocurrent- Voltage Relations in Ternary Organic Solar Cells
}

\author{
Wolfgang Tress, ${ }^{*}, \dagger \perp$ Beatrice Beyer, ${ }^{\ddagger}$ Negar Ashari Astani, ${ }^{\S}$ Feng Gao, ${ }^{\dagger}$ Simone Meloni, ${ }^{\S}$ \\ and Ursula Rothlisberger ${ }^{\S}$

\begin{abstract}
${ }^{\dagger}$ Biomolecular and Organic Electronics, IFM, Linköping University, 58183 Linköping, Sweden
${ }^{\ddagger}$ Fraunhofer Institute for Electron Beam, Plasma Technology and COMEDD (FEP), Maria-Reiche-Strasse 2, 01109 Dresden, Germany

${ }^{\S}$ Laboratoire de chimie et biochimie computationnelles, ISIC, FSB-BCH, École Polytechnique Fédérale de Lausanne (EPFL), CH-1015 Lausanne, Switzerland
\end{abstract}

Supporting Information

ABSTRACT: Efficient organic solar cells are based on (electron) donor-acceptor heterojunctions. An optically generated excited molecular state (exciton) is dissociated at this junction, forming a charge-transfer (CT) state in an intermediate step before the electron and hole are completely separated. The observed highly efficient dissociation of this Coulombically bound state raises the question on the dissociation mechanism. Here, we show that the observed high quantum yields of charge carrier generation and CT state dissociation are due to extended (and consequently weakly bound) CT states visible in absorption and emission spectra and first-principles calculations. Identifying a new geminate-pair loss mechanism via donor excimers, we find that the hole on the small-

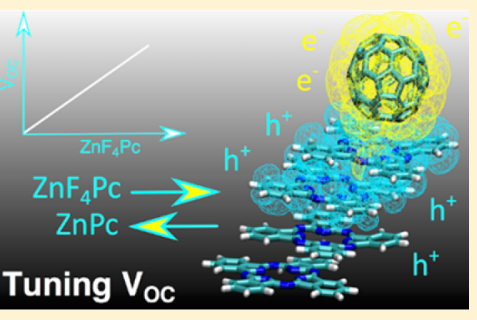
molecule donor is not localized on a single molecule and charge separation is correlated with the energetic offset between excimer and CT states. Thus, the charges upon interface charge transfer and even in the case of back-transfer and recombination are less localized than commonly assumed.

\begin{abstract}
A fter the discovery of the donor (D)-acceptor (A) concept, ${ }^{1}$ measurements showed that electron transfer from donor to acceptor is ultrafast ${ }^{2}$ (100s of fs). This charge transfer (CT) is needed to split the electron-hole pairs, which are photogenerated on the donor or acceptor as tightly bound localized Frenkel excitons due to the low dielectric constant of organic materials. The detailed path and driving forces toward a complete separation after CT are not fully understood. ${ }^{3}$ Energy offsets between the frontier orbitals and possibly changes in entropy ${ }^{4}$ play a major role. A CT state was found at the interface, which can be probed by direct optical transitions below the optical gap of the single molecules. ${ }^{5}$ It has been proposed that the CT state is an intermediate step on the way toward free charge carrier generation. Strong evidence for this is that the energetics and kinetics of the CT state determine the open-circuit voltage of the solar cell. ${ }^{5}$ The CT state is assumed to consist of an electronhole pair that is Coulombically bound, where binding energies in the range of $350 \mathrm{meV}$ are discussed based on the assumption of an initial distance of 1-2 $\mathrm{nm}$ after $\mathrm{CT}^{6}$ This binding energy $\gg k T$ contradicts the large quantum yields observed. That is why an initial distance that is increased by tunneling ${ }^{7}$ and further excited (so-called hot) CT states with excess energy have been proposed as the dominating path of charge dissociation. ${ }^{8,9}$ However, efficient dissociation of cool CT excitons upon direct optical excitation was shown experimentally. ${ }^{10,11}$

In this work, we directly show that extended CT states are fundamental in organic solar cells. To investigate the role of the surroundings on the energetics of the CT state, we employ
\end{abstract}

ternary blend systems, where a second very similar donor is added. The donors are $\mathrm{ZnPc}$ and a fluorinated derivative $\mathrm{ZnF}_{4} \mathrm{Pc}$ $\left(2,2^{\prime}, 2^{\prime \prime}, 2^{\prime \prime \prime}\right.$-tetrafluorophthalocyaninato zinc(II)). The acceptor is fullerene $\mathrm{C}_{60}$. The fluorination of $\mathrm{ZnPc}$ increases the ionization energy (IE) by $\sim 0.3 \mathrm{eV}$ (cf. Table. 2 ), whereas the optical gap remains almost constant (optical constants in the Supporting Information, Figure S1). We find that upon mixing the two donors interact with each other, creating CT and more extended states with orbitals spanning more than one donor molecule. Varying the composition of the blend tunes their energy values and the IE. In contrast to previous studies based on ultrafast spectroscopy, we employ steady-state measurements of photoluminescence (PL), electroluminescence (EL), and photocurrent spectroscopy together with first-principles calculations to directly relate properties of the CT states to changes in opencircuit voltage $\left(V_{\mathrm{oc}}\right)$ and in fill factor $(\mathrm{FF})$.

We investigate solar cell devices with varied $\mathrm{ZnF}_{4} \mathrm{Pc}: \mathrm{ZnPc}$ ratios, with the $\mathrm{C}_{60}$ content maintained at $60 \mathrm{wt} \%$. The bulk heterojunction is embedded in a pin-type solar cell: ITO (130 $\mathrm{nm}) / \mathrm{p}$-doped 9,9-bis[4-(N,N-bis( $p$-biphenyl-amino)phenyl]fluorene (BPAPF, $50 \mathrm{~nm}) / \mathrm{ZnF}_{4} \mathrm{Pc}: \mathrm{ZnPc} \mathrm{C}_{60}(38 \mathrm{~nm}) / \mathrm{C}_{60}(20$ $\mathrm{nm}) / n-\mathrm{C}_{60}(15 \mathrm{~nm}) / 200 \mathrm{~nm} \mathrm{Al}{ }^{12}$ The series with varying donor ratios is characterized by a $V_{\mathrm{oc}}$ that almost linearly increases with

Received: August 30, 2016

Accepted: September 19, 2016

Published: September 22, 2016 
$\mathrm{ZnF}_{4} \mathrm{Pc}$ content (Figure 1), as observed for other ternary systems as well. ${ }^{13,14}$ This trend is accompanied by a monotonous decrease of the FF.

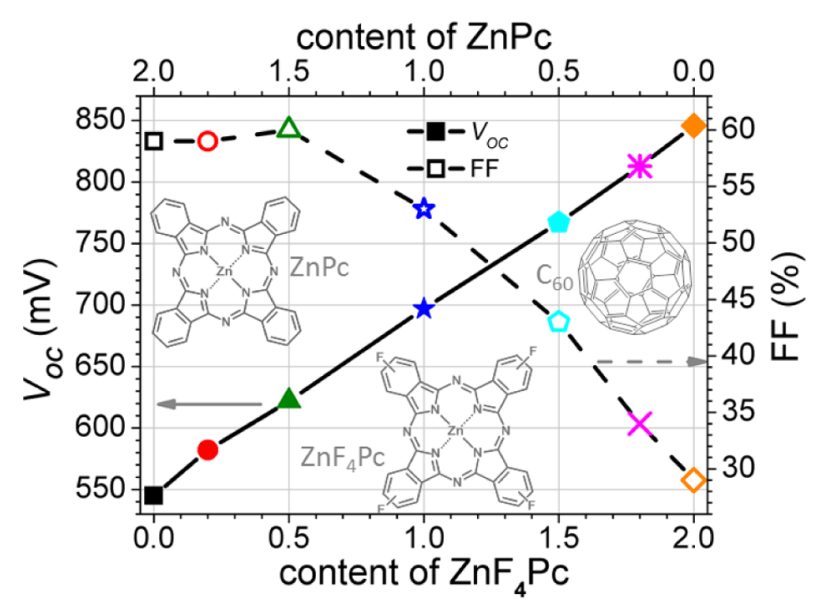

Figure 1. Open-circuit voltage $\left(V_{\mathrm{oc}}\right)$ and $\mathrm{FF}$ as a function of the $\mathrm{ZnF}_{4} \mathrm{Pc}$ content. The gray insets show the molecular structures of the active materials.
The values of $V_{\text {oc }}$ for the two binary blends $(0.55 \mathrm{vs} 0.85 \mathrm{~V})$ can be explained by changes in the effective HOMO-LUMO gap of the blend due to the shift in the HOMO of the donor. However, the values for the ternary systems cannot be explained by a simple parallel connection of $\mathrm{ZnPc}: \mathrm{C}_{60}$ and $\mathrm{ZnF}_{4} \mathrm{Pc}_{\mathrm{C}} \mathrm{C}_{60}$ heterojunctions. In that case, the heterojunction system with the lower voltage would limit $V_{\text {oc }}$. Instead, $V_{\text {oc }}$ values that lie in between those of the binary blends are observed. The explanation of such $V_{\text {oc }}$ values for the ternary systems requires either hot (thermally not equilibrated) charges, ${ }^{15}$ where holes on $\mathrm{ZnPc}$ phases are not in quasi-equilibrium with holes on $\mathrm{ZnF}_{4} \mathrm{Pc}$ phases, or the formation of a new effective medium with averaged energy levels.

To clarify whether hot charges or an effective medium are responsible for the trend of $V_{\text {oc }}$ we investigate optical transitions in the ternary systems. The absorption properties are studied by sensitive measurements of the external quantum efficiency (EQE) onset using Fourier-transform photocurrent spectroscopy (FTPS), ${ }^{16}$ accompanied by linear-response time-dependent density functional theory (LR-TDDFT) calculations (Figure 2). The main signal at higher energies results from absorption of $\mathrm{ZnPc}$ or $\mathrm{ZnF}_{4} \mathrm{Pc}$ molecules showing almost the same absorption spectra (Figure S1). ${ }^{17}$ Comparing mixtures with (a) and without $\mathrm{C}_{60}(\mathrm{~b})$, a shoulder at low energies appears that is obviously due to absorption into newly generated states upon blending the
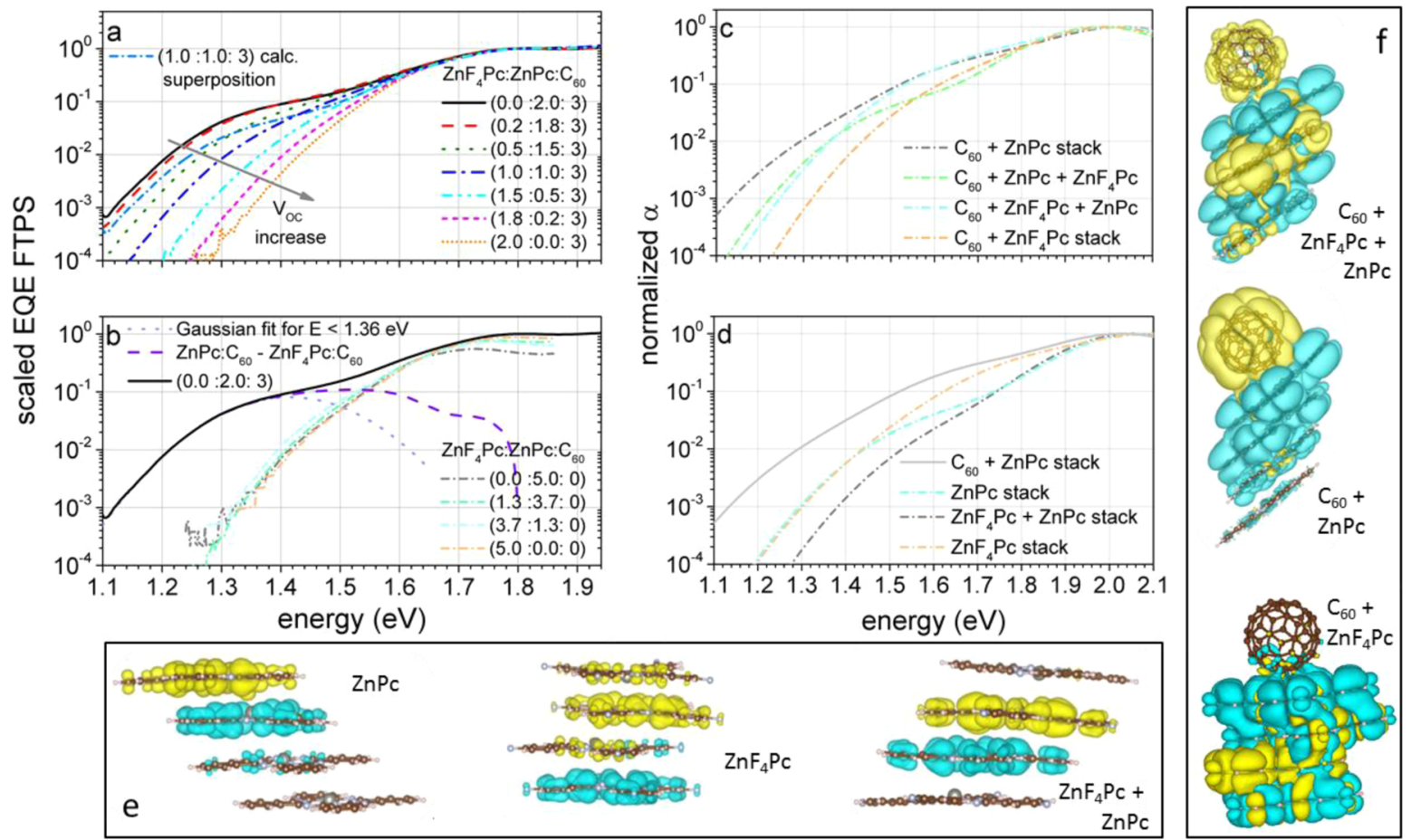

Figure 2. (a) EQE onset of the ternary blends measured by FTPS and normalized at $1.8 \mathrm{eV}$. The light blue dashed-dotted line visualizes a calculated 1:1 superposition of the $\mathrm{ZnPc}: \mathrm{C}_{60}$ and $\mathrm{ZnF}_{4} \mathrm{Pc}_{\mathrm{c}} \mathrm{C}_{60}$ spectra, which cannot describe the measured shifted spectra (dark blue for 1:1). (b) ZnPc: $\mathrm{C}_{60}$ EQE spectrum and additional spectra of $\mathrm{ZnF}_{4} \mathrm{Pc}: \mathrm{ZnPc}$ blends without $\mathrm{C}_{60}$. The low-energy signal is due to the $\mathrm{CT}$ state in blends with $\mathrm{C}_{60}$. It is broad and cannot be fitted by a single Gaussian, as visualized by the dotted and dashed lines. The latter gives an estimate for the minimum CT absorption of a $\mathrm{ZnPc}: \mathrm{C}_{60}$ blend because it is calculated as the difference between the spectra of the $\mathrm{ZnF}_{4} \mathrm{Pc}: \mathrm{C}_{60}$ and $\mathrm{ZnPc}: \mathrm{C}_{60}$ blends. The data for the $\mathrm{ZnF} \mathrm{Pc}_{4}: \mathrm{ZnPc}$ devices indicate that a CT state between the two donors (if existent) does not influence the low-energy part of the spectra. (c) Calculated LR-TDDFT/ M06 absorption spectra of CT excitations (with $>20 \%$ of the involved orbitals corresponding to excitations from stack to $\mathrm{C}_{60}$ orbitals) for binary and ternary blends following the experimental trend shown in (a) with novel excitations for the ternary systems with energies in between those of the binary ones almost independent of stacking sequence. (d) Calculated LR-TDDFT/M06 absorption spectra of CT excitations (with $\Lambda<0.7)$ for ZnPc $+\mathrm{C}_{60}$ and $\mathrm{Zn}\left(\mathrm{F}_{4}\right) \mathrm{Pc}$ stacks. The trends coincide with the experimental data in $(\mathrm{b})$. Due to the enhanced CT character $(\Lambda=0.3)$, the M06-2X functional is used for $\mathrm{ZnF}_{4} \mathrm{Pc}$. (e) Optimized structures and electron density differences of pure and mixed alternating donor stacks. Electrons (yellow) and holes (blue) are shown for the first excitation $\left(\rho_{1}-\rho_{0}\right)$ with separated but localized charges. (f) Optimized structures and electron density differences of blends with $\mathrm{C}_{60}$. Electrons (yellow) and holes (blue) are shown for a low-energy excitation of the spectra in (c), visualizing extended states. 
Table 1. Characteristic Parameters of a Ternary Solar Cell Series with Varied Donor Composition ${ }^{a}$

\begin{tabular}{|c|c|c|c|c|c|c|c|}
\hline $\mathrm{ZnF}_{4} \mathrm{Pc}: \mathrm{ZnPc} \mathrm{C}_{60}$ & $0.0: 2.0: 3$ & $0.2: 1.8: 3$ & $0.5: 1.5: 3$ & $1: 1: 3$ & $1.5: 0.5: 3$ & $1.8: 0.2: 3$ & $2.0: 0.0: 3$ \\
\hline$V_{\mathrm{oc}} / \mathrm{mV}$ & 545 & 582 & 622 & 697 & 767 & 813 & 846 \\
\hline $\mathrm{FF} / \%$ & 59 & 59 & 60 & 53 & 43 & 34 & 29 \\
\hline peak EL/eV & $<1.15$ & $\sim 1.16$ & $\sim 1.18$ & 1.22 & 1.27 & 1.32 & 1.35 \\
\hline $\mathrm{EQE}_{\mathrm{EL}}$ & $>1 \times 10^{-7}$ & $>2 \times 10^{-7}$ & $\sim 3 \times 10^{-7}$ & $7 \times 10^{-7}$ & $2 \times 10^{-6}$ & $2 \times 10^{-6}$ & $2 \times 10^{-6}$ \\
\hline FTPS at $0.1 \% / \mathrm{eV}$ & 1.12 & 1.13 & 1.18 & 1.21 & 1.27 & 1.32 & 1.35 \\
\hline FTPS Gauss 1st peak/eV & $1.42 \pm 0.01$ & $1.42 \pm 0.01$ & $1.47 \pm 0.02$ & $1.48 \pm 0.02$ & $1.54 \pm 0.04$ & $1.59 \pm 0.05$ & \\
\hline FTPS Gauss $\sigma / \mathrm{meV}$ & $99 \pm 2$ & $98 \pm 2$ & $101 \pm 3$ & $95 \pm 3$ & $96 \pm 8$ & $95 \pm 10$ & \\
\hline$V_{\text {oc,rad }} / \mathrm{V}$ & 0.97 & 0.98 & 1.03 & 1.06 & 1.12 & 1.17 & 1.19 \\
\hline$V_{\text {oc,calc }} / \mathrm{V}$ & $\sim 0.55$ & $\sim 0.58$ & $\sim 0.64$ & 0.69 & 0.78 & 0.83 & 0.85 \\
\hline
\end{tabular}

${ }^{a} V_{\text {oc,rad }}$ is the radiative limit for $V_{\text {oc }}$ obtained using a Gaussian fit to the calculated emission from the photovoltaic EQE (assuming an EQE of 70\% at $1.8 \mathrm{eV}$ ). For ZnPc-rich films, the peak position is estimated using a Gaussian fit to the high-energy part of the signal because the error of the detector below $1.2 \mathrm{eV}$ becomes too significant. The fitting of a Gaussian to the FTPS data is done at the onset, selecting a varied energy range to check the effect of the choice of energy interval on the obtained values for peak position and $\sigma$ of the Gaussian. This approach gives a rough estimation of errors, which allows one to judge peak shifts and broadening. $V_{\mathrm{oc}, \text { calc }}$ is estimated considering $V_{\mathrm{oc}, \mathrm{rad}}$ and the $\mathrm{EQE} \mathrm{EL}_{\mathrm{EL}}$.

donor(s) with $\mathrm{C}_{60}$. Those might be $\mathrm{CT}$ states, that is, in a simplified picture, a direct excitation of an electron in the HOMO of the donor into the LUMO of the $\mathrm{C}_{60} \cdot{ }^{18}$ More precisely, the interaction between donor and acceptor molecules creates a CT complex with new orbitals and optical transitions into excited states, which can have more or less CT character, as calculations show (Figure 2f). Hence, this absorption onset is a measure of the effective energy gap of the blend, ${ }^{5}$ and we assign it to the creation of an A/D electron-hole pair. The shift of the low-energy shoulder of $\sim 0.23 \mathrm{eV}$ roughly agrees with the $V_{\text {oc }}$ variation, which is a bit larger due to changes in the radiative recombination yield quantified by measuring the EQE of electroluminsence $\left(\mathrm{EQE}_{\mathrm{EL}}\right)$ given in Table 1. Fitting the onset with a Gaussian shows that the maxima shift, whereas the width remains unchanged (Table 1 and Figure S2). Thus, a superposition of separate $\mathrm{ZnPc}: \mathrm{C}_{60}$ and $\mathrm{ZnF}_{4} \mathrm{Pc}_{\mathrm{C}} \mathrm{C}_{60}$ junctions with different energies as simulated by the dashed-dotted light blue line in Figure 2a can be excluded. Instead, the energy of the $\mathrm{A} / \mathrm{D}$ electron-hole pair changes gradually with composition, as observed in refs 12 and 19. This trend is seen in the IE as well and interpreted based on long-range quadrupole interactions in ref 12 , which change polarization energies. Beyond these electrostatic interactions, we see the single absorption feature as strong evidence for the donor molecules interacting with each other and leading to states that are not completely localized on one molecule (further confirmed by DFT and TDDFT calculations vide infra). This is consistent with what has been proposed in recent studies based on ultrafast spectroscopy and quantumchemical and other modeling approaches. ${ }^{20-26}$ The absorption spectrum cannot sufficiently be described by a single Gaussian as commonly done motivated by Marcus theory ${ }^{27,28}$ but shows a broad character (purple dashed line in Figure 2b) containing a variety of transitions, as theoretically discussed below. Remarkably, this effect occurs although these blends are considered Xray amorphous ${ }^{29}$ and featureless down to the sub-10 nm length scale. Thus, even obviously disordered systems can show an extended CT state, most likely due to ordering in the nanometer length scale. ${ }^{30}$ We expect similar effects for polymer:fullerene systems as well (Figure S3).

Comparing the FTPS spectra of pure donors with donor mixtures in Figure $2 b$, an additional low-energy absorption upon mixing is not observed although it might be expected from a transition between the $\mathrm{HOMO}$ of a $\mathrm{ZnPc}$ and the $\mathrm{LUMO}$ of an adjacent $\mathrm{ZnF}_{4} \mathrm{Pc}$ molecule. As discussed in ref 12, phase separation can be excluded. Therefore, the missing low-energy shoulder indicates that there are no distinct HOMO and LUMO levels of the separate molecules in mixed films, which we additionally prove with the DFT-calculated IEs (and thus HOMOs). The DFT results (more details in Figures S11-18) show that with and without $\mathrm{C}_{60}$ a blend of $\mathrm{ZnPc}$ and $\mathrm{ZnF}_{4} \mathrm{Pc}$ exhibits an IE, energetically located in between the single compounds (Table 2). Systematic calculations of systems with

Table 2. Calculated IEs in $\mathrm{eV}$ at the (U)DFT/M06 Level of Theory for Single Molecules and Various Stacks

\begin{tabular}{|c|c|c|c|c|}
\hline \multicolumn{2}{|c|}{ Single Molecule } & \multicolumn{3}{|c|}{ Stack of Two Molecules } \\
\hline $\mathrm{ZnPc}$ & $\mathrm{ZnF}_{4} \mathrm{Pc}$ & $\mathrm{ZnPc}+\mathrm{ZnPc}$ & $\mathrm{ZnPc}+\mathrm{ZnF}_{4} \mathrm{Pc}$ & $\mathrm{ZnF}_{4} \mathrm{Pc}+\mathrm{ZnF}_{4} \mathrm{Pc}$ \\
\hline 6.00 & 6.28 & 5.78 & 5.99 & 6.07 \\
\hline \multicolumn{5}{|c|}{ Stack of Four Molecules } \\
\hline \multicolumn{2}{|c|}{$\begin{array}{c}\mathrm{ZnPc} / \mathrm{ZnPc} / \mathrm{ZnPc} / \\
\mathrm{ZnPc}\end{array}$} & \multicolumn{2}{|c|}{$\begin{array}{c}\mathrm{ZnPc} / \mathrm{ZnF}_{4} \mathrm{Pc} / \mathrm{ZnPc} / \\
\mathrm{ZnF}_{4} \mathrm{Pc}\end{array}$} & $\begin{array}{c}\mathrm{ZnF}_{4} \mathrm{Pc} / \mathrm{ZnF}_{4} \mathrm{Pc} / \mathrm{ZnF}_{4} \mathrm{Pc} / \\
\mathrm{ZnF}_{4} \mathrm{Pc}\end{array}$ \\
\hline \multicolumn{2}{|c|}{5.43} & \multicolumn{2}{|c|}{5.80} & 5.95 \\
\hline \multirow{2}{*}{\multicolumn{2}{|c|}{$\begin{array}{c}\mathrm{C}_{60}+\mathrm{ZnPc} / \\
\mathrm{ZnPc} / \mathrm{ZnPc} / \\
\mathrm{ZnPc}\end{array}$}} & \multicolumn{2}{|c|}{ Ternary and Binary Blends with $\mathrm{C}_{60}$} & \\
\hline & & $\begin{array}{r}\mathrm{C}_{60}+\mathrm{ZnPc}_{\text {and }} \mathrm{ZnF}_{4} \mathrm{I} \\
\text { and } \mathrm{C}_{60}+\mathrm{ZnF}_{4} \mathrm{Pc} \\
\mathrm{Zn}\end{array}$ & $\begin{array}{l}\mathrm{c} / \mathrm{ZnPc} / \mathrm{ZnF}_{4} \mathrm{Pc} \\
\mathrm{ZnPc} / \mathrm{ZnF}_{4} \mathrm{Pc} / \\
\mathrm{c}\end{array}$ & $\begin{array}{c}\mathrm{C}_{60}+\mathrm{ZnF}_{4} \mathrm{Pc} / \\
\mathrm{ZnF}_{4} \mathrm{Pc} / \mathrm{ZnF}_{4} \mathrm{Pc} / \\
\mathrm{ZnF}_{4} \mathrm{Pc}^{2}\end{array}$ \\
\hline \multicolumn{2}{|c|}{5.38} & 5.73 and 5.71 & respectively & 5.88 \\
\hline
\end{tabular}

increasing size (up to tetrameric stacks) show that this trend is independent of the size for both systems with and without $\mathrm{C}_{60}$. The IEs of the systems made by four molecule stacks and one $\mathrm{C}_{60}$ molecule are 5.38, 5.71, 5.73, and $5.88 \mathrm{eV}$, for $4 \mathrm{ZnPc}+\mathrm{C}_{60}$, $\mathrm{ZnPc} / \mathrm{ZnF}_{4} \mathrm{Pc} / \mathrm{ZnPc} / \mathrm{ZnF}_{4} \mathrm{Pc}+\mathrm{C}_{60}, \mathrm{ZnF}_{4} \mathrm{Pc} / \mathrm{ZnPc} / \mathrm{ZnF}_{4} \mathrm{Pc} /$ $\mathrm{ZnPc}+\mathrm{C}_{60}$, and $4 \mathrm{ZnF}_{4} \mathrm{Pc}+\mathrm{C}_{60}$, respectively. This clearly shows that the IE does not depend on whether a $\mathrm{ZnPc}$ or a $\mathrm{ZnF}_{4} \mathrm{Pc}$ molecule is adjacent to $\mathrm{C}_{60}$ but only on the composition of the stack.

The creation of a novel HOMO is typically not considered but has to be taken into account when designing a D/A pair for heterojunction solar cells. This common new HOMO state might explain why some polymer or small-molecule blends show very low photocurrent yields despite large frontier orbital energy offsets between single donor and acceptor molecules (e.g., $\mathrm{ZnPc}$ / $\mathrm{F}_{16} \mathrm{ZnPc}^{31}$ ).

Experimental FTPS spectra are compared with TDDFT ones obtained by including 60 excitations of stacks of 4 molecules for various $\mathrm{ZnPc} / \mathrm{ZnF}_{4} \mathrm{Pc}$ compositions, with (Figure $2 \mathrm{c}$ ) and without (Figure 2d) $\mathrm{C}_{60}$. It turns out that the inclusion of such a large number of excitations is necessary because each experimental peak corresponds to a number of energetically 

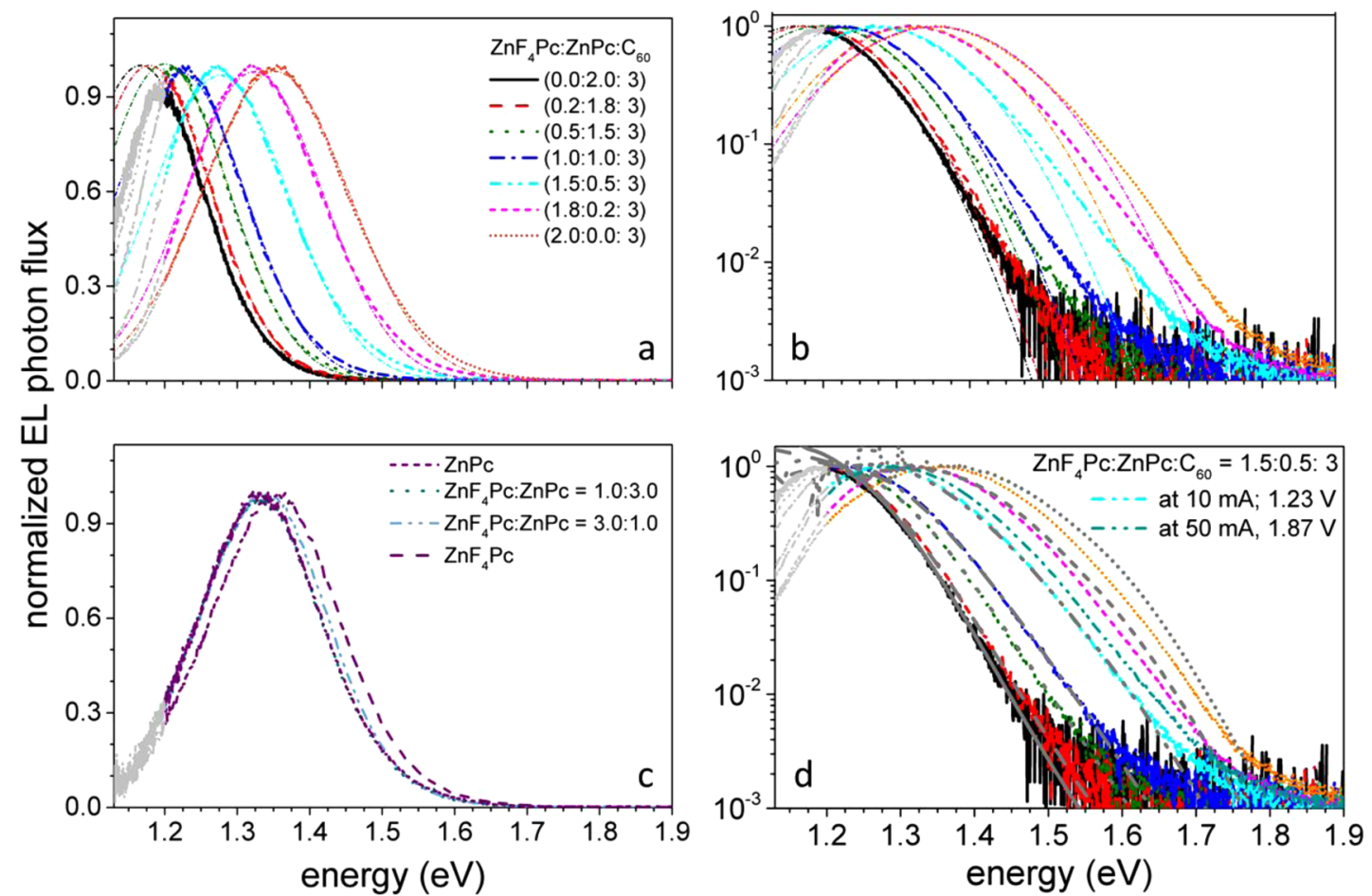

Figure 3. Normalized EL of ternary blends in (a) linear and (b) logarithmic scales showing a shift of the CT state EL with composition. Thin dasheddotted lines are Gaussian fits for energies larger than $1.2 \mathrm{eV}$. The high-energy region of all spectra cannot be fitted by a Gaussian but shows exponential decay, which is characteristic of a broad density of states. (c) EL of devices without $\mathrm{C}_{60}$ showing a peak at $1.35 \mathrm{eV}$. (d) Experimental EL spectra compared to those calculated from the reciprocity relation (gray) between photovoltaic EQE (Figure 2) and EL assuming a carrier temperature of $90-100^{\circ} \mathrm{C}$. The $\mathrm{ZnF}_{4}$ Pc-rich blends do not perfectly follow this relation due to emission from the donor excimer state at $1.35 \mathrm{eV}$ (which does not contribute to the photovoltaic EQE). This state can also be populated in the 1.5:0.5:3 blend if the driving voltage (shown is 1.87 vs $1.23 \mathrm{~V}$ ) is sufficiently large to induce tunneling into this state with energy larger than the CT state of this composition.

close-lying excitations. The agreement between the experimental and theoretical results is remarkable. Consistent with experimental data (Figure 2b), the calculated spectra of pure donor stacks are similar to each other, while the addition of $\mathrm{C}_{60}$ results in the formation of a pronounced shoulder at lower energies (Figure 2b,d). Also consistent with experimental results is the trend in the TDDFT spectra of ternary blends as a function of composition; the absorption onset of the mixed $\mathrm{ZnPc}+\mathrm{ZnF}_{4} \mathrm{Pc}$ $+\mathrm{C}_{60}$ system is in between that of $\mathrm{ZnPc}+\mathrm{C}_{60}$ and $\mathrm{ZnF}_{4} \mathrm{Pc}+\mathrm{C}_{60}$ (Figure 2a,c) and is independent of the termination of the stack, whether $\mathrm{ZnPc}$ or $\mathrm{ZnF}_{4} \mathrm{Pc}$ is adjacent to $\mathrm{C}_{60}$.

The electronic character of one of the lowest-energy excitations of the discussed spectra is shown in Figure 2e,f, where the electron density difference between the ground and the excited state is reported for $\mathrm{ZnPc}, \mathrm{ZnF}_{4} \mathrm{Pc}$, and mixed $\mathrm{ZnPc}+$ $\mathrm{ZnF}_{4} \mathrm{Pc}$ stacks with (f) and without (e) $\mathrm{C}_{60}$. In the case of the binary $\mathrm{ZnPc}+\mathrm{C}_{60}$ blend, the excitation has a clear $\mathrm{CT}$ character. Electrons (yellow) move from the donor to $\mathrm{C}_{60}$, leaving the extended hole (blue) on the $\mathrm{ZnPc}$ stack. In the ternary and $\mathrm{ZnF}_{4} \mathrm{Pc}_{\mathrm{c}} \mathrm{C}_{60}$ blends, $\mathrm{CT}$ from the stack to the $\mathrm{C}_{60}$ is less pronounced, probably due to the competition with $\mathrm{ZnF}_{4} \mathrm{Pc}$ as the acceptor. These qualitative observations are confirmed by quantification of the CT character through calculations of the so-called $\lambda$ parameter, ${ }^{32}$ as discussed in the Computational Methods section. Recently, other groups also reported similar observation (delocalization of the hole over several monomers upon excitation) for different $\pi$-stacked systems. ${ }^{33,34}$

Comparing the character of excitations of pure stacks with that of stacks with $\mathrm{C}_{60}$, the main role of the acceptor $\mathrm{C}_{60}$ is to help in spreading and separating charge even without a complete electron transfer to $\mathrm{C}_{60}$. This finding offers an explanation why blends with very low concentrations of either donor or acceptor work efficiently, ${ }^{35}$ although the low-concentration component does not provide charge transport paths toward the electrodes. Instead, the presence of this component is required to assist charge separation on the main component.

We further probe the energy of A/D electron-hole pairs by measuring the EL of injected charges that radiatively recombine in the blend. ${ }^{36}$ The shift of the spectra in Figure 3a,b follows the trend of absorption, as expected from fundamental reciprocity relations. ${ }^{37}$ The spectra of the ternaries again cannot be predicted by a superposition of the two binary spectra (Figure S4). Furthermore, the indicated Gaussian fits (dashed-dotted) do not fit the higher-energy region, which is characterized by an exponentially decaying function without additional features. This is further indication that the spectrum is not limited to a narrow Gaussian but made up of many transitions with a maintained density of states for larger energies and thermal exponential occupation statistics governing the tail.

Besides the shift for larger $\mathrm{ZnF}_{4} \mathrm{Pc}$ content, the EL turns out to be a superposition of two signals for $\mathrm{ZnF}_{4} \mathrm{Pc}$-rich blends. A second peak at $1.35 \mathrm{eV}$ is due to luminescence of a state on $\mathrm{ZnPc}$ and $\mathrm{ZnF}_{4} \mathrm{Pc}$ because it is seen in $\mathrm{EL}$ spectra of $\mathrm{ZnPc}, \mathrm{ZnF}_{4} \mathrm{Pc}$, and $\mathrm{ZnPc}: \mathrm{ZnF}_{4} \mathrm{Pc}$ devices without $\mathrm{C}_{60}$ (Figure 3c). The existence of this second peak with higher emission yield is confirmed by EL measurements as a function of the applied voltage and by comparing measured EL to calculated ${ }^{37}$ EL in Figure 3d. A larger voltage enhances this emission relative to emission from the A/D electron-hole pair if its energy is slightly larger than the one of the A/D electron-hole pair energy (visible and shown for 
$\mathrm{ZnF}_{4} \mathrm{Pc}: \mathrm{ZnPc}_{\mathrm{C}} \mathrm{C}_{60}$ 1.5:0.5:3; for the other blends, see Figure S5) because tunneling into this slightly higher energetic state is enhanced by the electric field. This correlation with energy is further indication for treating the energy of the A/D electronhole pair for the ternaries as an effective value. It is in accordance with the continuous shift in the threshold voltage of the dark currents in the $J-V$ curves of Figure S6, even for low concentrations of $\mathrm{ZnF}_{4} \mathrm{Pc}$, where one would expect that hole transport could be completely provided by the energetically favorable $\mathrm{ZnPc}$ molecules, which would not result in a shift. The gray lines in Figure 3d indicate that the measured EL spectra can be well-reproduced assuming a (carrier) temperature of 90-100 ${ }^{\circ} \mathrm{C}$. This temperature is not unrealistic for the used current densities, as measurements at organic light-emitting diodes show. ${ }^{38}$ The temperature might be overestimated if the higher energetic states show an increased emission yield. At large $\mathrm{ZnF}_{4} \mathrm{Pc}$ content or at high driving voltages in the case of the $\mathrm{ZnF}_{4} \mathrm{Pc}: \mathrm{ZnPc}: \mathrm{C}_{60}$ 1.5:0.5:3 device, the reciprocity does not hold any more, indicating that emission predominantly occurs via a state that does not contribute to the EQE with the same quantum efficiency.

To further investigate the emission at $1.35 \mathrm{eV}$, we compare PL of pure, binary, and ternary systems in more detail (Figure 4).

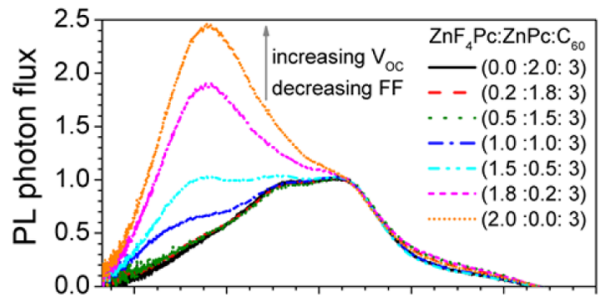

b

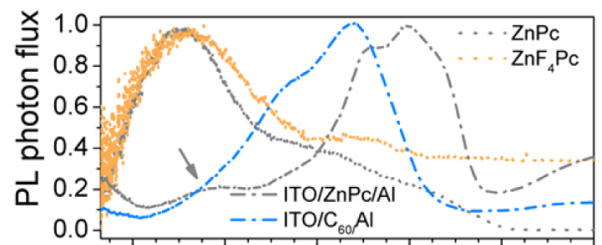

C

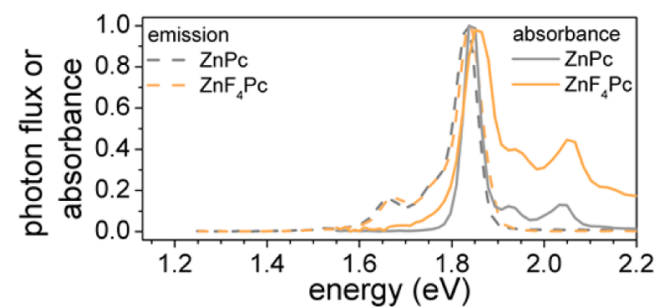

Figure 4. (a) PL of the ternary systems normalized at $1.66 \mathrm{eV}$. The higher the $\mathrm{ZnF}_{4} \mathrm{Pc}$ content, the more prominent the $\mathrm{PL}$ at around 1.35 $\mathrm{eV}$. Comparison of PL spectra of the pure materials in (b) films and (c) toluene. The molecular pure material PL of the donors between 1.6 and $1.9 \mathrm{eV}$ is mostly quenched in films (in some, it can be seen: gray dasheddotted), but the signal at $1.35 \mathrm{eV}$ is characteristic of all films containing $\mathrm{ZnPc}$ and/or $\mathrm{ZnF}_{4} \mathrm{Pc}$. It is attributed to excimer emission of the donors.

The ternaries show a prominent PL peak at $1.35 \mathrm{eV}$, hardly shifting with composition (panel a). However, the intensity decreases with increased $\mathrm{ZnPc}$ content and correlates with an increase of $V_{o c}$ and a decrease of the FF. Investigating the spectra in panel (b), we observe this peak in all films where $\mathrm{ZnPc}$ or $\mathrm{ZnF}_{4} \mathrm{Pc}$ is present. Thus, $\mathrm{PL}$ and $\mathrm{EL}$ at $1.35 \mathrm{eV}$ result from the same state, which is a lower-lying donor state compared to the single-molecule singlet state. As it is not seen in solution (panel c), we attribute it to excimer (or higher aggregate) emission that has been reported in that energy range, ${ }^{39}$ indicating a delocalization of charge over at least two donor molecules. The remaining luminescence of the ternaries with peaks at $1.66 \mathrm{eV}$ and close to $1.5 \mathrm{eV}$ (panel a) is supposed to result from pure material emission, most likely $\mathrm{C}_{60}{ }^{40}$ (blue dashed-dotted line in panel b). The emission of the A/D electron-hole pair is not clearly visible in the PL, in contrast to the EL. This is because its emissivity (see Table 1 for the EL yield of $\mathrm{ZnPc}$-rich films) is very low, lower than that for the excimer and the pure material. Thus, it is not clearly resolved in the PL measurement that is conducted at lower charge carrier concentrations compared to those injected when applying a voltage $>1 \mathrm{~V}$ for the EL measurements. The slight broadening in the low-energy region of the PL spectra for the $\mathrm{ZnF}_{4} \mathrm{Pc}: \mathrm{ZnPc}: \mathrm{C}_{60}$ 1.0:1.0:3 device might result from emission of the A/D electron-hole pair.

Regarding the correlation of the excimer emission with the FF, we anticipate that it is a loss mechanism, similar to triplet ${ }^{41}$ or singlet $^{42}$ states that are below the CT state. However, delocalization makes recombination through triplets unlikely. ${ }^{43}$ Thus, in the $\mathrm{ZnPc}$ system, despite low-energy triplets $(1.08 \mathrm{eV}$, $\left.1.15 \mu \mathrm{m}^{39}\right)$, triplets are no significant loss channel as $\mathrm{ZnPc}: \mathrm{C}_{60}$ devices show high internal quantum efficiencies and FFs. The PL spectra as a function of applied voltage prove that the PL emission at $1.35 \mathrm{eV}$ is quenched for larger reverse bias (shown for $\mathrm{ZnF}_{4} \mathrm{Pc}: \mathrm{ZnPc} \mathrm{C}_{60}$ 1.8:0.2:3 in Figure $\left.5 \mathrm{a}\right)$. Figure $5 \mathrm{~b}$ shows the quenching efficiency, which we define as unity minus the ratio of the PL at a certain voltage divided by the PL at open circuit. The dependence on voltage indicates that excimer emission is correlated with photocurrent and thus the FF for the devices with high $\mathrm{ZnF}_{4} \mathrm{Pc}$ content (cf. Figure 1). For the other devices, the overall recombination through the excimer is weaker (e.g., roughly $10 \%$ for the $1.0: 1.0: 3$ blend). Thus, only a small fraction recombines through the excimer, and the voltage dependence of this process seen in the quenching efficiency does not dominate but only slightly decreases the FF, which completely saturates at $60 \%$ for ZnPc-rich devices, where it is limited by charge transport. ${ }^{44}$ For the low FF devices, we rule out reasons related to transport of charges such as low charge carrier mobilities or high bimolecular recombination due to potential changes in morphology for ternary blends. This is because the molecular structure and morphology are similar, the FF remains high even for a $0.5: 1.5: 3$ blend, and a slightly modified $\mathrm{ZnF}_{4} \mathrm{Pc}^{29}$ (with a 0.1 $\mathrm{eV}$ higher HOMO) shows high performance. Also, fielddependent dissociation of a strongly bound electron-hole pair is ruled out as its binding energy is not expected to depend on the ternary composition. Consequently, it is most likely the energy of the excimer approaching the energy of the A/D electron-hole pair that governs the FF. We recognize that the luminescent recombination path does not represent the major recombination process due to low luminescence yields (cf. Table 1). However, assuming that the ratio between emissive and nonradiative recombination of the excimer state is independent of voltage, we can causally correlate quenching efficiency and FF.

The proposed scheme of photoinduced transitions is sketched in Figure 5c, involving localized pure-material transitions, spatially extended A/D electron-hole pairs, and donor emissive states (excimer). A remaining question is whether the loss through the excimer requires the formation of an $\mathrm{A} / \mathrm{D}$ electronhole pair first or whether the excimer is directly formed from the singlet. In other words, (i) does the electric field help to dissociate the excimer, (ii) does it affect the initial formation of the excimer (avoiding its formation), or (iii) does it drive the A/ 


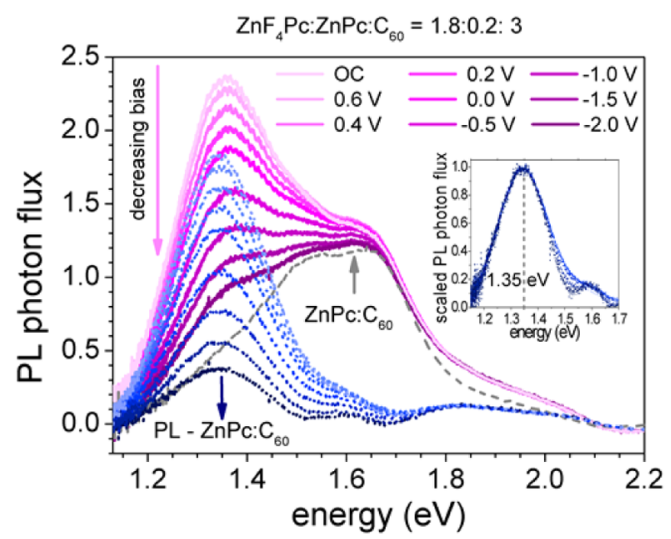

C

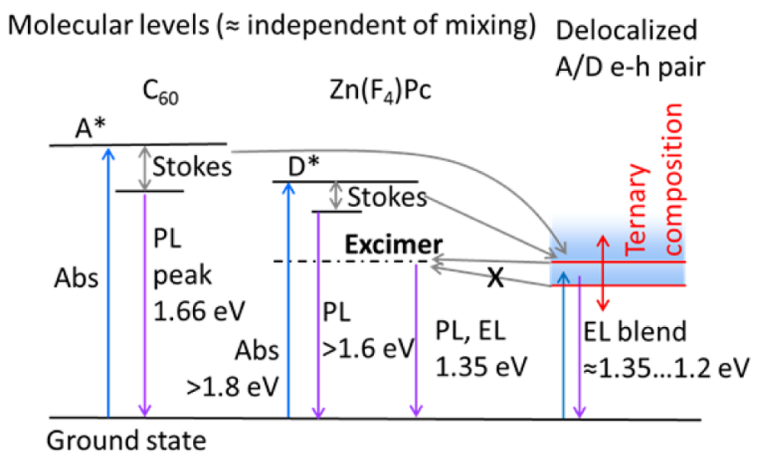

b

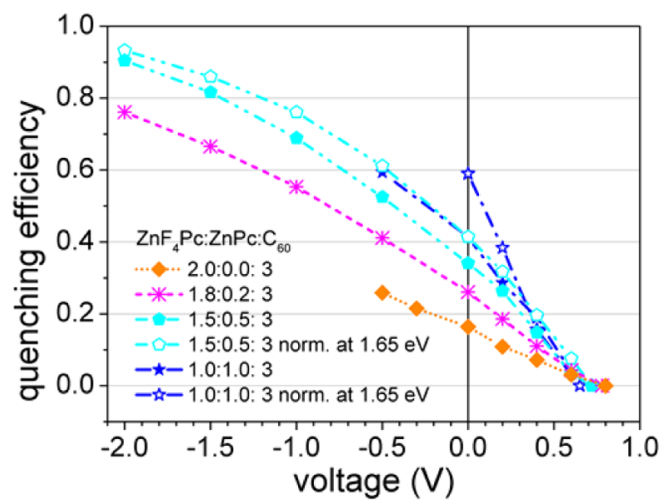

d

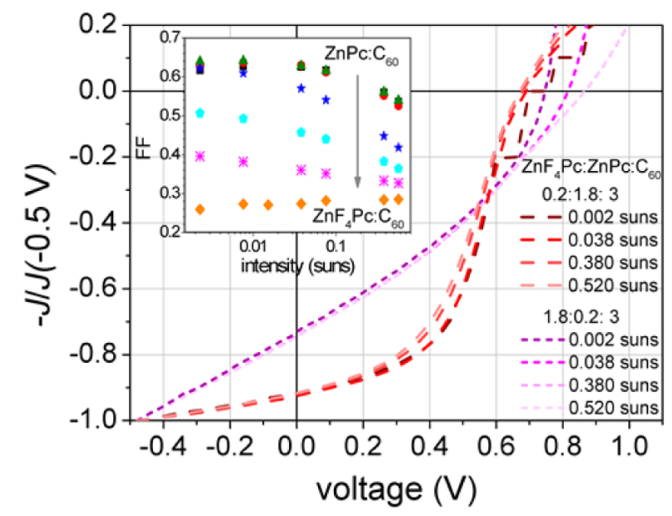

Figure 5. (a) $\mathrm{PL}$ as a function of voltage for device $\mathrm{ZnF}_{4} \mathrm{Pc}: \mathrm{ZnPc}: \mathrm{C}_{60}$ 1.8:0.2:3. Blue dotted lines are obtained after subtracting a scaled $\mathrm{ZnPc}: \mathrm{C}_{60}(\mathrm{gray}$ dashed) emission spectrum. The normalized spectra in the inset show that the signal is quenched without changing the shape of the spectrum. (b) PL quenching efficiency as a function of voltage for $\mathrm{ZnF}_{4} \mathrm{Pc}$-rich devices where the PL peak can be clearly observed at open circuit (cf. Figure $4 \mathrm{a}$ ). Accurately determining the quenching efficiency is difficult the lower the PL peak compared to the remaining PL is as subtraction of scaled spectra is required. Dependent on the point of normalization and reference spectra (thin-film optics), absolute values vary, but the trends are unchanged. (c) Proposed scheme for generation of the photocurrent. After CT from the donor or acceptor, a less localized A/D electron-hole pair is formed. Its energy depends on the composition as the energies for optical transitions (absorption and EL) change. For too high values, the excimer (or higher aggregate) state becomes accessible and back-transfer of charge occurs, as seen in excimer PL. (d) Photocurrent (current under illumination minus current in the dark) for different light intensities normalized at $-0.5 \mathrm{~V}$. The $\mathrm{ZnF}_{4} \mathrm{Pc}$-rich blend (short dashed) shows a normalized photocurrent-voltage curve that is independent of illumination intensity, indicating monomolecular recombination, whereas blends with larger ZnPc content (and higher FF) show a more significant dependence of photocurrent on voltage for larger intensities. This trend is also reflected in the FF as a function of illumination intensity shown in the inset.

D electron-hole pair apart to avoid the formation of the excimer on longer time scales? Option (i) is unlikely as the lifetime of excimers is low and its emission can be hardly quenched in the pure films. Consequently, once formed, an excimer will decay into the ground state with high probability independent of applied voltage. Option (ii) would mean that there is a difference in the EQE of photons absorbed on the donor and photons absorbed by an A/D electron-hole pair (CT band). The EQE should depend more strongly on voltage for absorption on the donor as this exciton might end up in the excimer, whereas the A/ $\mathrm{D}$ electron-hole pair is (almost) free. However, this is not the case, as shown by the EQE as a function of voltage (Figure S7). Thus, recombination happens after the electron-hole pair is formed, and further thermally excited CT states are irrelevant for the voltage dependence of the photocurrent, as recently shown in ref 11 . The $J-V$ data are in accordance with this observation as the internal quantum efficiency in reverse bias approaches almost equally high values (the same currents) for all devices, meaning that there is no ultrafast loss channel, which would hardly be influenced by moderate changes of the electric field.
To determine the recombination order through excimer states, PL emission and photocurrent are investigated as a function of illumination intensity. The PL quenching efficiency as a function of voltage is independent of illumination intensity (Figure S8), showing that it is a monomolecular process. The same holds for the photocurrent-voltage relation for $\mathrm{ZnF}_{4} \mathrm{Pc}$-rich devices (Figure 5d). The FF does not depend on illumination intensity for those devices, while it decreases with intensity for the $\mathrm{ZnPc}$ rich devices, where bimolecular recombination and possibly series resistance effects become important as excimer recombination is not seen and FFs are higher (inset). The monomolecular recombination is not due to trap-assisted recombination, as proven by the open-circuit voltage as a function of illumination intensity, showing a slope of $60 \mathrm{mV} /$ decade characteristic for direct recombination (Figure S9). First, this verifies once more that there are not distinct HOMO levels as $\mathrm{ZnPc}$ should form a significantly deep trap $(0.3 \mathrm{eV})$ in $\mathrm{ZnF}_{4} \mathrm{Pc}$ rich blends. Second, the A/D electron-hole pairs geminately recombine when forming the excimer. Despite being almost free, charges recombine as geminate pairs and not bimolecularly as the 
distance to the next-available photogenerated charge is in temporal and spatial average on the order of $100 \mathrm{~nm}\left(10^{15}\right.$ charges $\mathrm{cm}^{-3}=1$ charge per $(100 \mathrm{~nm})^{3}$ cube $)$. The approximately linear photocurrent-voltage relation is indicative of a loss process that is in competition to a drift current. This observation implies that geminate recombination happens on the time scale of field-driven charge transport (ns) and challenges the idea based on Monte Carlo modeling, stating that separation happens by diffusion-driven ultrafast hops of hot carriers, ${ }^{45}$ which recombine bimolecularly on longer time scales. Thus, more sophisticated simulation approaches, in particular, for low light intensities, including charge delocalization might be required. $^{46}$

In conclusion we have shown that the photogenerated electron-hole pair on donors and acceptors extends over several molecules. Even geminate recombination happens through a rather delocalized donor state (excimer or higher aggregate), which is populated when its energy is close to the energy of the electron-hole pair on donors and acceptors. Independent of excess energy and the method of creation, the energetics of the $\mathrm{A} / \mathrm{D}$ electron-hole pair is determined by the donor mixture. This explains the high quantum efficiencies in organic solar cells and is in accordance with experimental observations that a certain amount of nanocrystallinity or ordering is required for good performance and, thus, is essential for all types of smallmolecule and polymer solar cells. The observed shift of frontier orbitals in blend systems has furthermore fundamental importance because it could open the path for novel design routes for organic semiconductors on the intermolecular level, allowing for continuously tunable energies.

\section{EXPERIMENTAL DETAILS}

For solar cell fabrication, glass substrates covered with $130 \mathrm{~nm}$ of ITO (LUMTEC) were structured by laser ablation. The active area $\left(A=0.15 \mathrm{~cm}^{2}\right)$ was defined by insulating passivation layers (SD-paste passiv, ESL Europe). Prior to deposition of the organic layers, the structured substrates were treated with acetone, and i-propanol and cleaned in a detergent bath (2\& Deconex FPD 211) at $40{ }^{\circ} \mathrm{C}$ with ultrasound for $7 \mathrm{~min}$. After that, they were rinsed with water and i-propanol and dried under nitrogen flow. Afterward, the substrates were heated for $20 \mathrm{~min}$ on a hot plate at $110^{\circ} \mathrm{C}$. The cover glasses were treated with an equivalent cleaning procedure but were dried for $120 \mathrm{~min}$ at $250{ }^{\circ} \mathrm{C}$. Organic materials and aluminum were evaporated in a custom-made vacuum chamber (BesTec) at a pressure of $10^{-7}$ mbar. For processing reasons, the commercially available p- (NDP-9) and n-dopants (NDN-26) from Novaled AG were used. After deposition of the solar cell samples, the substrates were encapsulated under a nitrogen atmosphere with a cavity glass (covered with a $\mathrm{CaO}$ getter) using UV-sensitive glue from Nagase.

The solar cell stack was in detail: glass $(0.7 \mathrm{~mm}) / \mathrm{ITO}(130$ $\mathrm{nm}) /$ p-doped 9,9-bis[4-(N,N-bis $(p$-biphenyl-amino $)$ phenyl $]$ fluorene (BPAPF, $50 \mathrm{~nm}) / \mathrm{ZnF}_{4} \mathrm{Pc}_{\mathrm{ZnPc}} \mathrm{C}_{60}(38 \mathrm{~nm}) / \mathrm{C}_{60}(20$ $\mathrm{nm}) / n-\mathrm{C}_{60}(15 \mathrm{~nm}) / 200 \mathrm{~nm} \mathrm{Al}$. The $\mathrm{C}_{60}$-free $\mathrm{ZnPc}$ and $\mathrm{ZnF}_{4} \mathrm{Pc}$ control samples contained Spiro-TTB:NDP-9 $(50 \mathrm{~nm})$ as a pdoped hole-transport layer and a BPhen $(10 \mathrm{~nm}) / \mathrm{Al}(130 \mathrm{~nm})$ cathode. Samples with $150 \mathrm{~nm}$ thick layers of $\mathrm{ZnPc}$ and $\mathrm{ZnF}_{4} \mathrm{Pc}$ on glass were prepared for additional PL measurements.

Current density voltage $(J-V)$ characteristics were recorded using a source measurement unit including a digital multimeter (Keithley 2000 DMM), a Kepco power supply, and a silicon reference solar cell connected via a shuntbox. A metal halide lamp was used to simulate the solar spectrum for global irradiation according to CIE (AM 1.5). If not otherwise noted, the illumination intensity was kept at $100 \mathrm{~mW} / \mathrm{cm}^{2}$, and the temperature was fixed at $25{ }^{\circ} \mathrm{C}$. In order to accurately define the illuminated area, a mask was used $\left(A=0.12 \mathrm{~cm}^{2}\right)$.

Current-voltage curves as a function of illumination intensity were measured using blue and red high-intensity light-emitting diodes. The intensity was adjusted by the driving current, calibrated with a silicon diode, and expressed in sun-intensity equivalents by comparing the short-circuit current densities of solar and similar LED illumination.

EQE spectra were recorded using a FTPS setup. It consisted of a Vertex 70 FT-IR spectrometer from Bruker, which was operated at the external detector option. Detecting the photocurrent (instead of transmission), the solar cell served as the specimen and the detector.

PL and EL spectra were detected using a light guide positioned close to the devices. The detector was a Newton EM-CCD Si array detector at $-60{ }^{\circ} \mathrm{C}$ with a Shamrock sr 303i spectrograph from Andor Tech. For the PL, a blue laser ( $405 \mathrm{~nm}, 5 \mathrm{~mW}$, spot size few $\mathrm{mm}^{2}$ ) was used as the excitation source; for the EL, the voltage was applied with a Keithley 2400 SMU. The sensitivity of the $\mathrm{Si}$ array extended to approximately $1.1 \mathrm{eV}$, where a calibration could not be used to accurately correct the signal between 1.2 and $1.1 \mathrm{eV}$. That is why the data in this spectral range were not trusted and shown in gray color in all figures.

\section{COMPUTATIONAL METHODS}

Geometry optimization of compounds in their singlet ground state were performed with DFT using the $\mathrm{M} 6^{47}$ functional and the effective core potential and basis set LANL2DZ ${ }^{48}$ for zinc and a $6-31 \mathrm{G}^{* 49}$ basis set for the remaining atoms. Additional diffuse basis functions were added on fluorine atoms. Calculations were performed with the Gaussian 09 package. ${ }^{50}$

The ternary blend was prepared in four steps of separate geometry optimizations starting with optimization of the single molecules, followed by stacks of dimers and tetrameres and, finally, the addition of the $\mathrm{C}_{60}$ molecule. At each step, the optimized geometry was used as the initial building block for the next system. The systems obtained after each geometry optimization step are shown in Figure SI15. The optimized geometries were similar to those predicted by Dwyer et al. in their classical force field approach. ${ }^{51}$ The polarizable continuum model (PCM) using the integral equation formalism variant $(\text { IEFPCM })^{52}$ was employed for treating solvation effects. Iodobenzene with a dielectric constant of $\sim 3.5-4.5$ was chosen to mimic the permittivity of the experimental blend. Geometry optimizations were followed by frequency calculations to ensure that the molecular configurations were minima of the corresponding ground-state potential energy surface. The M06 meta hybrid functional was chosen because its performance on related chlorophyll systems is well-established. ${ }^{53}$ For each system, LR-TDDFT/M06/IEF-PCM calculations were performed for the first 30 and, for smaller systems, 50 and 60 excited states, using the same basis set and $\mathrm{XC}$ functional. The extent of CT character was quantified via the diagnostic $\Lambda$ (Lambda parameter) as defined by Peach et al., ${ }^{54}$ which is a measure of the spatial orbital overlap of electrons and holes in a given excitation. $\Lambda$ values for binary and ternary blends are in the range of $0.3-0.6$, which is within the recommended window for applications of the M06 functional. Ternary blends with higher $\mathrm{ZnPc}$ concentration present lower $\Lambda$ values, confirming the higher amount of $\mathrm{CT}$ in these blends. For pure $\mathrm{ZnF}_{4} \mathrm{Pc}$ stacks, we 
used the M06-2X functional as prescribed by Li et al. ${ }^{32}$ to capture the enhanced CT character $(0.2<\Lambda<0.3)$ of the first excitation. To mimic EQE measurements in Figure 2c, we included only CT excitations that produce current, that is, excitations that transfer electrons from the stack to $\mathrm{C}_{60}$. To select the excitations of the stacks that produce current in Figure $2 \mathrm{~d}$ instead, we calculated the $\Lambda$ values and included excitations with $\Lambda<0.7$. The latter procedure could not be applied to $\mathrm{C}_{60}+$ stacks because even low $\Lambda$ can refer to CT excitations within the stack and not necessarily to those transferring electrons to the acceptor, making a choice based on visual inspection of the involved orbitals necessary.

Vertical IEs were computed at the (U)DFT/M06 level of theory. Graphical representations of the molecules and their orbitals were obtained using the VESTA package. ${ }^{55}$

\section{ASSOCIATED CONTENT}

\section{S Supporting Information}

The Supporting Information is available free of charge on the ACS Publications website at DOI: 10.1021/acs.jpclett.6b01962.

Additional spectroscopy data, device characterization, and further details on the modeling (PDF)

\section{AUTHOR INFORMATION}

\section{Corresponding Author}

*E-mail: wolfgang.tress@epfl.ch.

\section{Present Address}

${ }^{\perp}$ W.T.: Laboratory of Photonics and Interfaces, ISIC, Swiss Federal Institute of Technology (EPFL), CH 1015 Lausanne, Switzerland.

\section{Notes}

The authors declare no competing financial interest.

\section{ACKNOWLEDGMENTS}

The authors thank Olle Inganäs, Karl Leo, Martin Schwarze, and Reinhard Scholz for fruitful discussions. The research at Linköping was supported by the Knut and Alice Wallenberg Foundation through a Wallenberg Scholar grant to Olle Inganäs and by the Swedish Research Council. F.G. acknowledges financial support of the European Commission under a Marie Curie Intra-European Fellowship for Career Development. PRACE is acknowledged for awarding us access to computer resources at Supermuc at LRZ. U.R. acknowledges funding from the Swiss National Science foundation via individual Grant No. 200020-146645, the NCCRs MUST and MARVEL, and the NRP70 as well as support from the Swiss National Computing Center (CSCS) and the CADMOS project for computing resources.

\section{REFERENCES}

(1) Tang, C. W. Two-layer Organic Photovoltaic Cell. Appl. Phys. Lett. 1986, 48, 183-185.

(2) Brabec, C. J.; Zerza, G.; Cerullo, G.; De Silvestri, S.; Luzzati, S.; Hummelen, J. C.; Sariciftci, S. Tracing Photoinduced Electron Transfer Process in Conjugated Polymer/fullerene Bulk Heterojunctions in Real Time. Chem. Phys. Lett. 2001, 340, 232-236.

(3) Bässler, H.; Köhler, A. "Hot or Cold": How Do Charge Transfer States at the Donor-acceptor Interface of an Organic Solar Cell Dissociate? Phys. Chem. Chem. Phys. 2015, 17, 28451-28462.

(4) Gregg, B. A. Entropy of Charge Separation in Organic Photovoltaic Cells: The Benefit of Higher Dimensionality. J. Phys. Chem. Lett. 2011, 2, 3013-3015.
(5) Vandewal, K.; Tvingstedt, K.; Gadisa, A.; Inganäs, O.; Manca, J. V. On the Origin of the Open-Circuit Voltage of Polymer-fullerene Solar Cells. Nat. Mater. 2009, 8, 904-909.

(6) Clarke, T. M.; Durrant, J. R. Charge Photogeneration in Organic Solar Cells. Chem. Rev. 2010, 110, 6736-6767.

(7) Caruso, D.; Troisi, A. Long-Range Exciton Dissociation in Organic Solar Cells. Proc. Natl. Acad. Sci. U. S. A. 2012, 109, 13498-13502.

(8) Jailaubekov, A. E.; Willard, A. P.; Tritsch, J. R.; Chan, W.-L.; Sai, N.; Gearba, R.; Kaake, L. G.; Williams, K. J.; Leung, K.; Rossky, P. J.; et al. Hot Charge-Transfer Excitons Set the Time Limit for Charge Separation at Donor/acceptor Interfaces in Organic Photovoltaics. Nat. Mater. 2012, 12, 66-73.

(9) Bakulin, A. A.; Rao, A.; Pavelyev, V. G.; van Loosdrecht, P. H. M.; Pshenichnikov, M. S.; Niedzialek, D.; Cornil, J.; Beljonne, D.; Friend, R. H. The Role of Driving Energy and Delocalized States for Charge Separation in Organic Semiconductors. Science 2012, 335, 1340-1344.

(10) Lee, J.; Vandewal, K.; Yost, S. R.; Bahlke, M. E.; Goris, L.; Baldo, M. A.; Manca, J. V.; Voorhis, T. V. Charge Transfer State Versus Hot Exciton Dissociation in Polymer-Fullerene Blended Solar Cells. J. Am. Chem. Soc. 2010, 132, 11878-11880.

(11) Vandewal, K.; Albrecht, S.; Hoke, E. T.; Graham, K. R.; Widmer, J.; Douglas, J. D.; Schubert, M.; Mateker, W. R.; Bloking, J. T.; Burkhard, G. F.; et al. Efficient Charge Generation by Relaxed Charge-Transfer States at Organic Interfaces. Nat. Mater. 2014, 13, 63-68.

(12) Schwarze, M.; Tress, W.; Beyer, B.; Gao, F.; Scholz, R.; Poelking, C.; Ortstein, K.; Günther, A. A.; Kasemann, D.; Andrienko, D.; et al. Band Structure Engineering in Organic Semiconductors. Science 2016, $352,1446-1449$

(13) Khlyabich, P. P.; Burkhart, B.; Thompson, B. C. Efficient Ternary Blend Bulk Heterojunction Solar Cells with Tunable Open-Circuit Voltage. J. Am. Chem. Soc. 2011, 133, 14534-14537.

(14) Khlyabich, P. P.; Burkhart, B.; Thompson, B. C. Compositional Dependence of the Open-Circuit Voltage in Ternary Blend Bulk Heterojunction Solar Cells Based on Two Donor Polymers. J. Am. Chem. Soc. 2012, 134, 9074-9077.

(15) Savoie, B. M.; Dunaisky, S.; Marks, T. J.; Ratner, M. A. The Scope and Limitations of Ternary Blend Organic Photovoltaics. Adv. Energy Mater. 2015, 5, 1400891.

(16) Vandewal, K.; Goris, L.; Haeldermans, I.; Nesládek, M.; Haenen, K.; Wagner, P.; Manca, J. V. Fourier-Transform Photocurrent Spectroscopy for a Fast and Highly Sensitive Spectral Characterization of Organic and Hybrid Solar Cells. Thin Solid Films 2008, 516, 71357138.

(17) Brinkmann, H.; Kelting, C.; Makarov, S.; Tsaryova, O.; Schnurpfeil, G.; Wöhrle, D.; Schlettwein, D. Fluorinated Phthalocyanines as Molecular Semiconductor Thin Films. Phys. Status Solidi A 2008, 205, 409-420.

(18) Goris, L.; Haenen, K.; Nesládek, M.; Wagner, P.; Vanderzande, D.; De Schepper, L.; D'haen, J.; Lutsen, L.; Manca, J. V. Absorption Phenomena in Organic Thin Films for Solar Cell Applications Investigated by Photothermal Deflection Spectroscopy. J. Mater. Sci. 2005, 40, 1413-1418.

(19) Street, R. A.; Davies, D.; Khlyabich, P. P.; Burkhart, B.; Thompson, B. C. Origin of the Tunable Open-Circuit Voltage in Ternary Blend Bulk Heterojunction Organic Solar Cells. J. Am. Chem. Soc. 2013, 135, 986-989.

(20) Bernardo, B.; Cheyns, D.; Verreet, B.; Schaller, R. D.; Rand, B. P.; Giebink, N. C. Delocalization and Dielectric Screening of Charge Transfer States in Organic Photovoltaic Cells. Nat. Commun. 2014, DOI: $10.1038 /$ ncomms4245.

(21) Falke, S. M.; Rozzi, C. A.; Brida, D.; Maiuri, M.; Amato, M.; Sommer, E.; De Sio, A.; Rubio, A.; Cerullo, G.; Molinari, E.; et al. Coherent Ultrafast Charge Transfer in an Organic Photovoltaic Blend. Science 2014, 344, 1001-1005.

(22) Gélinas, S.; Rao, A.; Kumar, A.; Smith, S. L.; Chin, A. W.; Clark, J.; van der Poll, T. S.; Bazan, G. C.; Friend, R. H. Ultrafast Long-Range Charge Separation in Organic Semiconductor Photovoltaic Diodes. Science 2014, 343, 512-516. 
(23) Ma, H.; Troisi, A. Direct Optical Generation of Long-Range Charge-Transfer States in Organic Photovoltaics. Adv. Mater. 2014, 26, 6163-6167.

(24) Tamura, H.; Burghardt, I. Ultrafast Charge Separation in Organic Photovoltaics Enhanced by Charge Delocalization and Vibronically Hot Exciton Dissociation. J. Am. Chem. Soc. 2013, 135, 16364-16367.

(25) Sharifzadeh, S.; Wong, C. Y.; Wu, H.; Cotts, B. L.; Kronik, L.; Ginsberg, N. S.; Neaton, J. B. Relating the Physical Structure and Optoelectronic Function of Crystalline TIPS-Pentacene. Adv. Funct. Mater. 2015, 25, 2038-2046.

(26) Tscheuschner, S.; Bässler, H.; Huber, K.; Köhler, A. A Combined Theoretical and Experimental Study of Dissociation of Charge Transfer States at the Donor-Acceptor Interface of Organic Solar Cells. J. Phys. Chem. B 2015, 119, 10359-10371.

(27) Gould, I. R.; Noukakis, D.; Gomez-Jahn, L.; Young, R. H.; Goodman, J. L.; Farid, S. Radiative and Nonradiative Electron Transfer in Contact Radical-Ion Pairs. Chem. Phys. 1993, 176, 439-456.

(28) Vandewal, K.; Tvingstedt, K.; Gadisa, A.; Inganäs, O.; Manca, J. V. Relating the Open-Circuit Voltage to Interface Molecular Properties of Donor:acceptor Bulk Heterojunction Solar Cells. Phys. Rev. B: Condens. Matter Mater. Phys. 2010, 81, 125204.

(29) Meiss, J.; Merten, A.; Hein, M.; Schuenemann, C.; Schäfer, S.; Tietze, M.; Uhrich, C.; Pfeiffer, M.; Leo, K.; Riede, M. Fluorinated Zinc Phthalocyanine as Donor for Efficient Vacuum-Deposited Organic Solar Cells. Adv. Funct. Mater. 2012, 22, 405-414.

(30) Schindler, W.; Wollgarten, M.; Fostiropoulos, K. Revealing Nanoscale Phase Separation in Small-Molecule Photovoltaic Blends by Plasmonic Contrast in the TEM. Org. Electron. 2012, 13, 1100-1104.

(31) Suzuki, A.; Mizuno, A.; Oku, T.; Akiyama, T.; Yamasaki, Y. Fabrication and Characterization of Heterojunction Solar Cells of Hexadecafluorophthalocyanine/metal Phthalocyanine. Proc. SPIE 2011, $8409,84092 \mathrm{~F} / 1-84092 \mathrm{~F} / 8$.

(32) Li, R.; Zheng, J.; Truhlar, D. G. Density Functional Approximations for Charge Transfer Excitations with Intermediate Spatial Overlap. Phys. Chem. Chem. Phys. 2010, 12, 12697-12701.

(33) Fornari, R. P.; Aragó, J.; Troisi, A. Exciton Dynamics in Phthalocyanine Molecular Crystals. J. Phys. Chem. C 2016, 120, 79877996.

(34) Sung, J.; Kim, P.; Fimmel, B.; Würthner, F.; Kim, D. Direct Observation of Ultrafast Coherent Exciton Dynamics in Helical $\pi$-Stacks of Self-Assembled Perylene Bisimides. Nat. Commun. 2015, 6, 8646.

(35) Zhang, M.; Wang, H.; Tian, H.; Geng, Y.; Tang, C. W. Bulk Heterojunction Photovoltaic Cells with Low Donor Concentration. Adv. Mater. 2011, 23, 4960-4964.

(36) Tvingstedt, K.; Vandewal, K.; Gadisa, A.; Zhang, F.; Manca, J.; Inganäs, $\mathrm{O}$. Electroluminescence from Charge Transfer States in Polymer Solar Cells. J. Am. Chem. Soc. 2009, 131, 11819-11824.

(37) Rau, U. Reciprocity Relation between Photovoltaic Quantum Efficiency and Electroluminescent Emission of Solar Cells. Phys. Rev. B: Condens. Matter Mater. Phys. 2007, 76, 85303.

(38) Sugiyama, T.; Tsuji, H.; Furukawa, Y. Temperature Measurements of the PEDOT-PSS Layer in a Polymer Light-Emitting Diode by Stokes and Anti-Stokes Raman Scattering. Chem. Phys. Lett. 2008, 453, 238-241.

(39) Yoshino, K.; Hikida, M.; Tatsuno, K.; Kaneto, K.; Inuishi, Y. Emission Spectra of Phthalocyanine Crystals. J. Phys. Soc. Jpn. 1973, 34, 441-445.

(40) Reber, C.; Yee, L.; McKiernan, J.; Zink, J. I.; Williams, R. S.; Tong, W. M.; Ohlberg, D. A. A.; Whetten, R. L.; Diederich, F. Luminescence and Absorption Spectra of Carbon (C60) Films. J. Phys. Chem. 1991, 95, 2127-2129.

(41) Veldman, D.; Meskers, S. C. J.; Janssen, R. A. J. The Energy of Charge-Transfer States in Electron Donor-Acceptor Blends: Insight into the Energy Losses in Organic Solar Cells. Adv. Funct. Mater. 2009, 19, 1939-1948.

(42) Faist, M. A.; Kirchartz, T.; Gong, W.; Ashraf, R. S.; McCulloch, I.; de Mello, J. C.; Ekins-Daukes, N. J.; Bradley, D. D. C.; Nelson, J. Competition between the Charge Transfer State and the Singlet States of Donor or Acceptor Limiting the Efficiency in Polymer:Fullerene Solar Cells. J. Am. Chem. Soc. 2012, 134, 685-692.

(43) Rao, A.; Chow, P. C. Y.; Gélinas, S.; Schlenker, C. W.; Li, C.-Z.; Yip, H.-L.; Jen, A. K.-Y.; Ginger, D. S.; Friend, R. H. The Role of Spin in the Kinetic Control of Recombination in Organic Photovoltaics. Nature 2013, 500, 435-439.

(44) Tress, W.; Merten, A.; Furno, M.; Hein, M.; Leo, K.; Riede, M. Correlation of Absorption Profile and Fill Factor in Organic Solar Cells: The Role of Mobility Imbalance. Adv. Energy Mater. 2013, 3, 631-638.

(45) Vithanage, D. A.; Devižis, A.; Abramavičius, V.; Infahsaeng, Y.; Abramavičius, D.; MacKenzie, R. C. I.; Keivanidis, P. E.; Yartsev, A.; Hertel, D.; Nelson, J. Visualizing Charge Separation in Bulk Heterojunction Organic Solar Cells. Nat. Commun. 2013, DOI: $10.1038 /$ ncomms3334.

(46) Gagorik, A. G.; Mohin, J. W.; Kowalewski, T.; Hutchison, G. R. Effects of Delocalized Charge Carriers in Organic Solar Cells: Predicting Nanoscale Device Performance from Morphology. Adv. Funct. Mater. 2015, 25, 1996-2003.

(47) Zhao, Y.; Truhlar, D. G. The M06 Suite of Density Functionals for Main Group Thermochemistry, Thermochemical Kinetics, Noncovalent Interactions, Excited States, and Transition Elements: Two New Functionals and Systematic Testing of Four M06-Class Functionals and 12 Other Functionals. Theor. Chem. Acc. 2008, 120, 215241.

(48) Hay, P. J.; Wadt, W. R. Ab Initio Effective Core Potentials for Molecular Calculations. Potentials for K to Au Including the Outermost Core Orbitals. J. Chem. Phys. 1985, 82, 299-310.

(49) Hehre, W. J.; Ditchfield, R.; Pople, J. A. Self-Consistent Molecular Orbital Methods. XII. Further Extensions of Gaussian-Type Basis Sets for Use in Molecular Orbital Studies of Organic Molecules. J. Chem. Phys. 1972, 56, 2257-2261.

(50) Frisch, M. J.; Trucks, G. W.; Schlegel, H. B.; Scuseria, G. E.; Robb, M. A.; Cheeseman, J. R.; Scalmani, G.; Barone, V.; Mennucci, B.; Petersson, G. A.; et al. Gaussian 09, revision D.01; Gaussian, Inc.: Wallingford, CT, 2009.

(51) Dwyer, P. J.; Vander Valk, R. J.; Caltaldo, V.; Demianicz, D.; Kelty, S. P. All-Atom CHARMM Force Field and Bulk Properties of Perfluorozinc Phthalocyanines. J. Phys. Chem. A 2014, 118, 1158311590.

(52) Cossi, M.; Rega, N.; Scalmani, G.; Barone, V. Energies, Structures, and Electronic Properties of Molecules in Solution with the C-PCM Solvation Model. J. Comput. Chem. 2003, 24, 669-681.

(53) Mathew, S.; Yella, A.; Gao, P.; Humphry-Baker, R.; Curchod, B. F. E.; Ashari-Astani, N.; Tavernelli, I.; Rothlisberger, U.; Nazeeruddin, M. K.; Grätzel, M. Dye-Sensitized Solar Cells with 13\% Efficiency Achieved through the Molecular Engineering of Porphyrin Sensitizers. Nat. Chem. 2014, 6, 242-247.

(54) Peach, M. J. G.; Benfield, P.; Helgaker, T.; Tozer, D. J. Excitation Energies in Density Functional Theory: An Evaluation and a Diagnostic Test. J. Chem. Phys. 2008, 128, 044118.

(55) Momma, K.; Izumi, F. VESTA: A Three-Dimensional Visualization System for Electronic and Structural Analysis. J. Appl. Crystallogr. 2008, 41, 653-658. 